Bull. Egypt. Soc. Physiol. Sci. Vol. (41) Issue (1), 84- 95

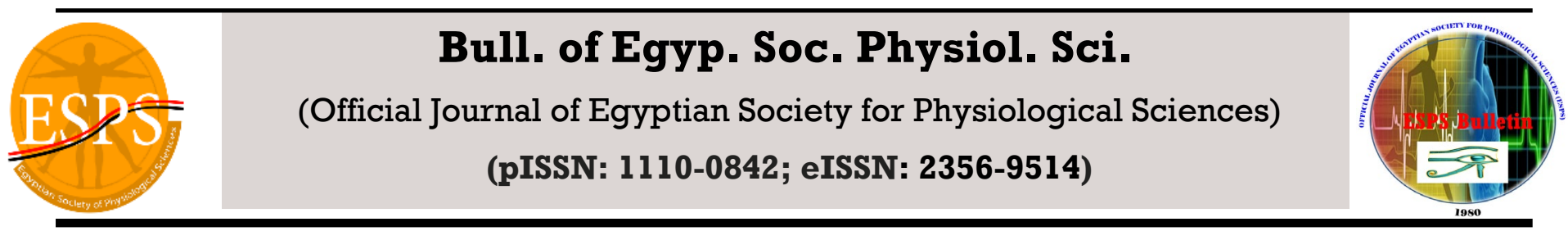

\title{
Effect of Diabetes Mellitus on Uterine contractility in Pregnant Rat Model: Possible Role of $L$-carnitine
}

\author{
Eman A. Wagih ${ }^{1}$, Amr M Abbas ${ }^{1,2}$, Soheir Farid ${ }^{1,}$ Assad El-Meligy ${ }^{1}$ Soheir Abbas $^{1}$ \\ ${ }^{1}$ Medical Physiology Department, Faculty of Medicine, Mansoura University, Egypt \\ ${ }^{2}$ Medical Physiology Department, College of Medicine, King Khalid University, KSA
}

Submit Date: May 2, 2020

Accept Date: May 28, 2020

Available Online : Jan 1, 2021

Keywords

1-CARNITINE

Uterine contractility

Diabetes

\section{Abstract}

Objective: to detect the changes induced by STZ- induced diabetes on uterine contractility and expression of connexin 43 in pregnant rat and the possible role of Lcarnitine to detect the role of L-Carnitine in a model of diabetic pregnant rat.

Method:40 female Sprague Dawley rats were subdivided into four groups; G I (NC): normal pregnant rats, G II (DI): in which rats received single i.p injection of $40 \mathrm{mg} / \mathrm{kg}$ b.wt STZ at day 1 of pregnancy, G III (DI+CAR): in which rats received STZ as above, and then at day 3 of pregnancy, diabetic pregnant rats received daily i.p L-carnitine injection at a dose of $100 \mathrm{mg} / \mathrm{kg}$ b.wt till end of pregnancy, and G IV (DI+INS): in which rats received STZ as above, and then at day 3 of pregnancy, diabetic pregnant rats received daily i.p insulin injection at a dose of $1 \mathrm{IU} / 100 \mathrm{~g}$ b.wt (till end of pregnancy. Plasma glucose and insulin level, uterine contractility, pathological changes were assessed at the end of the experiment and scarifying of rats.

Results: STZ induced DM caused significant increase in plasma glucose level, decreased plasma insulin level, impaired uterine contractility, pathological changes in diabetic group compared to normal control group. L-Carnitine caused significant improvement in the studied parameters.

Conclusion: L-Carnitine has beneficial effect against GDM in rats.

Corresponding author: Eman Abdallah Wagih , 0502031701, physiology department, faculty of medicine, Mansoura University, el mansoura ,Egypt. E-mail zienababdallah@mans.edu.eg, 


\section{Introduction}

Gestational diabetes (GDM) is defined as any abnormal carbohydrate intolerance resulting in hyperglycemia of variable severity with onset or first recognition during pregnancy (1). GDM accounts for approximately $90 \%$ of all diabetescomplicated pregnancies and has a range of detrimental effects on pregnancy outcome, including effects on delivery as well as during the neonatal period (2).

There is controversy about the effect of diabetes on uterine contractility during pregnancy as many studies have revealed that diabetes is associated with failure of labor induction and prolonged labor (3), also, Postpartum hemorrhage due to poor myometrial contractility is reported to be more common in diabetic women (4). However, some studies revealed that hyperglycemia during pregnancy increase the risk of premature delivery (5)

L-Carnitine is a natural vitamin-like compound, is a ubiquitous constituent of mammalian plasma and tissues, mainly distributed among skeletal and cardiac muscles. L-Carnitine is supplied to the body through dietary sources (e.g., meat, dairy products), and by biosynthesis from lysine and methionine. L-Carnitine functions to transport long chain fatty acids across the inner mitochondrial membrane into the matrix for $\beta$ oxidation and has effects on oxidative metabolism of glucose in tissues (6).

Since there is controversy about the effect of diabetes on uterine contractility during pregnancy, we will investigate this effect. We hypothesize that diabetes may impair uterine contractility through many mechanisms involving oxidative stress, apoptosis and causing change in connexin 43 expressions.

\section{Aim of work}

To study the changes induced by STZ-induced diabetes on uterine contractility in pregnant rat and the possible protective role of $\mathrm{L}$-carnitine.

\section{Material and methods:}

\section{Experimental animals}

32 adult female Sprague Dawley rats weighting 200-250 grams were enrolled in this study. Animals were bred and housed in the animal house of the Medical Experimental Research center (MERC), Mansoura University, at controlled environmental conditions (temperature of $24^{\circ} \mathrm{C}$ and $12 \mathrm{hrs}$ light/dark cycles) fed a standard laboratory chow and had a free access to tap water. All experimental protocols were approved by our local committee of animal care and ethics.

\section{Experimental design}

Rats were divided into four groups; G I (NC): normal pregnant rats, G II (DI): in which rats received single i.p injection of $40 \mathrm{mg} / \mathrm{kg}$ b.wt STZ at day 1 of pregnancy(7), G III (DI+CAR): in which rats received STZ as above, and then at day 3 of pregnancy, diabetic pregnant rats received daily i.p L-carnitine injection at a dose of 100 $\mathrm{mg} / \mathrm{kg}$ b.wt (8) till end of pregnancy, and G IV (DI+INS): in which rats received STZ as above, and then at day 3 of pregnancy, diabetic pregnant rats received daily i.p insulin injection at a dose of $1 \mathrm{IU} / 100 \mathrm{~g}$ b.wt (9) till end of pregnancy,

\section{Induction of pregnancy}

Vaginal smears, taken daily from the female rats, were examined by using light microscope to ensure that they were in in regular estrous cycle. The female proved to be in estrus phase was paired with a mature male rat in a separate cage for 24 
hours. In the next morning, a vaginal smear was taken and copulation was confirmed by the presence of copulation plug or spermatozoa in the vagina. The presence of sperms or vaginal plug was designated gestational day 0 (G0) (10).

\section{Induction of diabetes}

Rats received single i.p injection of $40 \mathrm{mg} / \mathrm{kg}$ b.wt STZ at day 1 of pregnancy (7). STZ was dissolved in $0.1 \mathrm{~mol} / \mathrm{L}$ citrate buffer solutions (11). Rats were allowed to drink $10 \%$ glucose solution for 24-hours following STZ injection to avoid STZ induced initial hypoglycemia (12). 48-hours after STZ-injection, the blood glucose level were estimated via rat tail vein blood samples using the One Touch Blood Glucose Monitoring System. Rats with blood glucose levels $>300 \mathrm{mg} / \mathrm{dl}$ were included in the study (13).

\section{Collection of blood and tissue samples}

\section{a. Collection of blood samples:}

At the end of the experiment (at the day 20 of pregnancy), animals were anethesitized with i.p injection of thiopental in a dose of $120 \mathrm{mg} / \mathrm{kg}$ (14). After anaesethia, blood was collected from the heart by cardiac puncture in EDTA-containing tube and the blood was centrifuged for $15 \mathrm{~min}$ at $3000 \mathrm{rpm}$ then the plasma was aspirated and kept frozen at $-20{ }^{\circ} \mathrm{C}$ until used for analysis of plasma glucose and insulin level.

\section{b. Collection of uterine tissues}

After collection of blood samples the abdomen was opened, the uterine horns were dissected, transferred immediately to a dish containing the physiological salt (De Jalone solution) (PSS) solution, cleaned of the connective fat, placenta, fetus, and fetal membrane, and then the endometrium was scrubbed and rinsed sloughly with cold saline solution.
Afterwards, the two horns were divided and one horn was taken for detection of pathological changes, while the other horn was used for recording uterine contractility.

\section{Recording of uterine contractility:}

Uterine contractility was recorded on a Lap-top using the PowerLab data acquisition system (Lab Chart 7, AD Instruments, Medical physiology department, Mansoura University).A full-thickness longitudinal myometrial strip $(10 \mathrm{~mm}$ long and 2 $\mathrm{mm}$ wide) was rapidly obtained from the antimesenteric edge of the uterine horn and Muscle strips were placed vertically in the organ bath and tied at the bottom end to a fixed metal hook and at the top end to an isometric transducer using a silk thread. The isometric transducer was connected to a bridge amplifier and to the PowerLab data acquisition system with chart 7 software (AD Instrument, power lab 4/30, Australia). The organ bath contained physiological salt (De Jalone) solution (PSS) with the following composition (g/L): NaCl 9.00, $\mathrm{KCl} \mathrm{0.42,} \mathrm{CaCl} 2$ 0.06, $\mathrm{NaHCO} 3$ 0.50 and glucose 0.50, $\mathrm{PH} 7.4$ (15), warmed at 37

$\circ \mathrm{C}$ and bubbled with $95 \% \mathrm{O}_{2}$ and $5 \% \mathrm{CO}_{2}$ throughout the experimental period.

Each uterine strip was allowed to equilibrate under optimum resting force of $1 \mathrm{~g}$ for 60 minutes to accommodate the new medium until spontaneous rhythmic contractions (basal contractility) were recorded.

After equilibration, spontaneous uterine contractions were recorded and the base line tone, amplitude and frequency of contractions were recorded. Tone was measured as the deviation from base line, amplitude was measured as the maximal peaks of contractions over the period time, then the mean and standard deviation were 
calculated, and frequency of contractions were measured as number of contraction/relaxation cycles in the control period time.

After recording basal contractions oxytocin induced uterine contractility was recorded by its in vitro addition of oxytocin $\left(10^{-9}\right)$ (16) to the organ bath solution. oxytocin induced uterine contractions were assessed by changes in the resting tone, amplitude of rhythmic contractions, and frequency of rhythmic contraction.

\section{Biochemical analysis}

\section{a) Estimation of plasma glucose}

Glucose was determined by the method described by (17) using commercial kit (Human).

\section{b) Estimation of plasma insulin}

Plasma insulin level was determined using rat insulin ELISA kit (18) purchased from Sun Red biological technology company.

\section{Histopathological study}

The uterine tissues collected from all experimental groups, were washed with saline immediately, and then fixed in solution of $10 \%$ buffered neutral formalin. After fixation, the uterine tissue was processed by embedding in paraffin, sectioned, and stained with hematoxylin and eosin (H\&E).

\section{Statistical analysis}

Statistical analysis of the data was done by using statistical package for social science (SPSS) version 15.0. The data were expressed as Mean \pm $\mathrm{SD}$. Comparison for parametric data were carried out by analysis of variance (ANOVA) followed by Tukey's post hoc analysis for intergroup multiple comparisons. All graphic representation of the data were performed with microsoft ${ }^{\circledR}$ Excel ${ }^{\circledR}$ for windows ${ }^{\circledR}$ (Microsoft Inc., USA).

\section{Results}

\section{Biochemical analysis}

a. Plasma glucose level

Table (1) demonstrates the changes in fasting plasma glucose level. Plasma glucose level was significantly increased in (DI) when compared to (NC).Plasma glucose level was significantly decreased $(\mathrm{DI}+\mathrm{CAR})$ when compared to (DI). Also, significantly decreased in (DI+INS) when compared to (DI) and (DI+CAR).

b. Plasma insulin level

Table (1) demonstrates the changes in fasting plasma insulin level. Plasma insulin level was significantly decreased in DI group when compared to $\mathrm{NC}$ group. Plasma insulin level showed significant decreased in DI+CAR group when compared to $\mathrm{NC}$ group, while showed nonsignificant change when compared to DI group. Also, there was significant increase in plasma insulin level in DI+INS group (GIV) when compared to DI and DI+CAR groups.

\section{Uterine contractility changes}

a. Spontaneous uterine contractility:

Table (2) and figure (1) showed significant decrease in amplitude and frequency of spontaneous uterine contractility in DI group when compared to $\mathrm{NC}$ group. Basal amplitude and frequency was significantly increased in DI+CAR group to DI group. Also, there was significant increase in basal amplitude and frequency in DI+INS group when compared to DI and DI+CAR groups.

\section{Oxytocin induced uterine contractility:}

There was an increase in the frequency and tone of uterine contractility after adding oxytocin to the solution in all studied groups as presented in table (2) and figure (1).The percentage increase in the 
frequency in comparison with the basal frequency of spontaneous uterine contractility was (92.5 $\pm 2.78 \%), \quad(54.38 \pm 3.62 \%), \quad(70.13 \pm 6.73 \%)$, and by $(80.25 \pm 0.463 \%)$ in DI (GII), DI+CAR (GIII), and DI+INS (GIV) groups respectively.

Tone increased by $(0.821 \pm 0.056)$ in comparison with the basal tone of spontaneous uterine contractility in NC group. In DI group, tone increased by $(0.267 \pm 0.01)$ and significantly increased in DI+CAR group when compared to DI group. Also, there was significant increase in tone in DI+INS group when compared to DI DI+CAR groups.

\section{Histopathological study}

Figure $(2, \mathrm{a})$ represents $\mathrm{NC}$ group, where uterus displays normal endometrium with normal endometrial glands, normal stroma and normal lining columnar epithelium. DI group (figure2, b) showed uterine endometrium with atrophied glands and inflammatory exudate in the supporting stroma. DI+CAR group (figure2, c) showed uterine endometrium with slightly atrophied glands and edema in the supporting stroma, while DI+INS group (GIV) (figure2, d) showed normal uterine endometrium with normal endometrial glands and edema in the supporting stroma.

Table (1): Plasma glucose and insulin level in different studied groups.

\begin{tabular}{|c|c|c|c|c|c|}
\hline Group & $\begin{array}{c}\text { NC } \\
\text { G: I }\end{array}$ & GI & $\begin{array}{c}\text { DI+ CAR } \\
\text { G:III }\end{array}$ & $\begin{array}{c}\text { DI+ INS } \\
\text { G:IV }\end{array}$ & $\begin{array}{c}\text { DI+Com } \\
\text { G: V }\end{array}$ \\
\hline $\begin{array}{l}\text { Glucose } \\
(\mathrm{mg} / \mathrm{dl})\end{array}$ & $76.25 \pm 1.67$ & $341.25 \pm 8.3^{*}$ & $296.88 \pm 9.6^{* \#}$ & $80.75 \pm 1.16 \# ¥$ & $78.31 \pm 0.89 \# ¥$ \\
\hline $\begin{array}{l}\text { Insulin } \\
\mu \mathrm{IU} / \mathrm{L}\end{array}$ & $13.89 \pm 0.51$ & $2.75 \pm 0.28^{*}$ & $2.81 \pm 0.33^{*}$ & $4.33 \pm 0.21 * \# ¥$ & $4.98 \pm 0.96^{* \# \#}$ \\
\hline
\end{tabular}

Table (2): Changes in different parameters of uterine contractility

\begin{tabular}{|c|c|c|c|c|c|}
\hline Group & Control & DI & DI+CAR & DI+ INS & DI+Com \\
& G :1 & G:II & G:III & G:IV & G: V \\
\hline Basal & $1.75 \pm$ & $0.498 \pm$ & $0.601 \pm$ & $0.828 \pm$ & $1.063 \pm 0.051$ \\
amplitude(gm) & 0.0399 & $0.001^{*}$ & $0.001 * \#$ & $0.013^{*} \# ¥$ & $* \# ¥ \dagger$ \\
\hline Basal frequency & $17.99 \pm$ & $7.25 \pm$ & $8.125 \pm$ & $10.25 \pm$ & $17.35 \pm 0.535$ \\
& 0.534 & $0.463^{*}$ & $0.354 * \#$ & $0.464^{*} \# ¥$ & $\# ¥ \dagger$ \\
\hline \% change in & $92.5 \pm 2.78$ & $54.38 \pm 3.62^{*}$ & $70.13 \pm 6.73$ & $80.25 \pm 0.463$ & 88 \\
frequency & & & $* \#$ & $* \# ¥$ & $\# ¥ \dagger$ \\
\hline Average tone & $0.821 \pm 0.056$ & $0.267 \pm 0.01 *$ & $0.367 \pm 0.01$ & $0.521 \pm 0.01$ & $0.659 \pm 0.03$ \\
& & & $* \#$ & $* \# ¥$ & $* \# ¥ \dagger$ \\
\hline
\end{tabular}

carnitine, DI+INS $(\mathrm{GIV})=$ diabetic group treated

All results are expressed as mean $\pm \mathrm{SD}$, (significance at $\mathrm{p} \leq 0.05), \mathrm{NC}(\mathrm{GI})=$ normal control, DI $(\mathrm{GII})=$ untreated diabetic group, $\mathrm{DI}+\mathrm{CAR}(\mathrm{GIII})=$ diabetic group treated with 1- with insulin, DI + Com $(\mathrm{GV})=$ diabetic group treated with both 1- carnitine and insulin, *=significant vs. GI, \#= significant vs. GII, $¥=$ significant vs. GIII, $\uparrow=$ significant vs. GIV. 

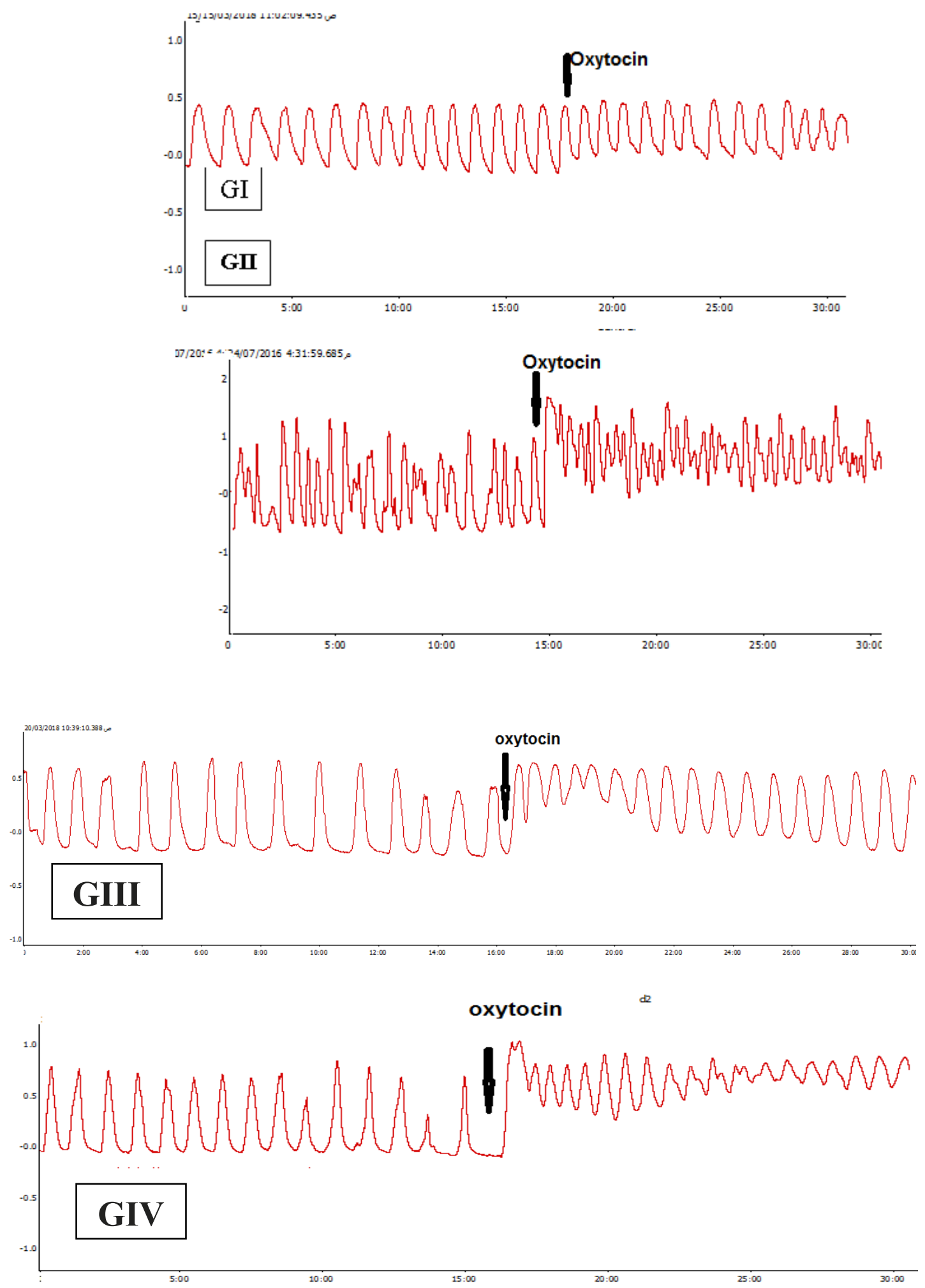

Figure (1): uterine contractility in different studied groups (GI): normal control group, (GII) untreated diabetic group, (GIII): diabetic group treated with L-carnitine, (GIV): diabetic group treated with insulin. 


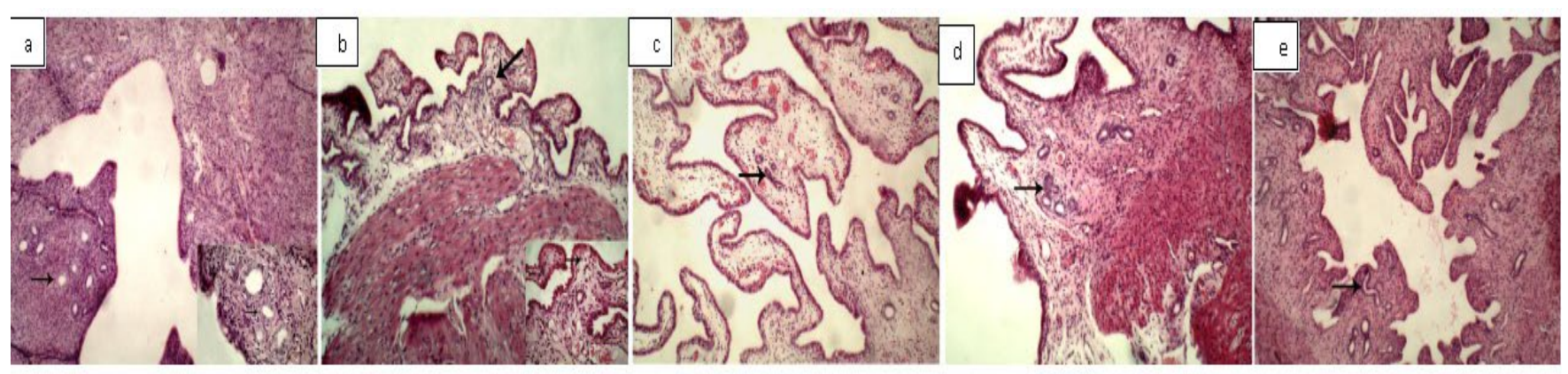

Figure (2): pathological changes by HX\&E. a: (NC group) uterus displays normal endometrium with normal endometrial glands (arrow), normal stroma and normal lining columnar epithelium (NC group), b: (DI group) uterus displays endometrium with atrophied glands (arrow) and inflammatory exudate in the supporting stroma, c: (DI+ L-carnitine group) uterus displays endometrium with slightly atrophied glands (arrow) and edema in the supporting stroma, d: (DI+INS group) uterus displays normal endometrium with normal endometrial glands (arrow), and edema in the supporting stroma.

\section{Discussion}

In the present study, a documented model of diabetic pregnant rat was used to study the effect of insulin and L-Carnitine on different parameters known to be disturbed in that model. In this study GDM was induced by a single intraperitoneal injection of STZ. It is an agent which destroys the insulin producing pancreatic $\beta$ - cells, it acts through breaking DNA strand in pancreatic islets and stimulation of nuclear poly (ADP ribose) synthetase and as a result it leads to depletion of the intracellular NAD and NADP levels. NAD depletion by STZ leads to inhibition of pro-insulin synthesis and as a sequence diabetes is induced (19).

Plasma glucose level was significantly increased in untreated diabetic group. This result is in agreement with the previous studies reporting hyperglycemia after STZ injection (20). That elevation in plasma glucose level was accompanied by decline in the plasma insulin level which may be caused by $\beta$-cells destruction by STZ. In STZ induced diabetes mellitus, there is failure in insulin production by $\beta$-cells, and the decreased plasma insulin level limits glucose utilization by insulin sensitive tissues and elevated blood glucose level (21).

Administration of L- Carnitine resulted in significant decrease in plasma glucose level. This effect may be due to an enhancing effect of LCarnitine on glucose utilization in diabetes, or by activating pyruvate dehydrogenase, or by decreasing intermitochondrial acetyl $\mathrm{CoA} / \mathrm{CoA}$ ratio (22). This results cope with the study performed by (23) who reported that L-Carnitine at a dose of $100 \mathrm{mg} / \mathrm{kg}$ for 4 weeks had significantly reduced blood glucose level in diabetic rat. However, these findings are in disagreement with (21) who reported that LCarnitine in a dose of $600 \mathrm{mg} / \mathrm{kg}$ /day orally for 6 weeks didn't have any lowering effect on elevated blood glucose level.

L-Carnitine treated group showed non-significant increase in insulin secretion in comparison with untreated diabetic group and this copes with (23) who suggested that L-Carnitine didn't affect insulin secretion however, these results are in disagreement with (24), the study illustrated that these effects were mediated via elevation of serum adiponectin which in turn elevates PPAR $\gamma$ which promotes insulin sensitivity, improve insulin 
receptor signaling in diabetes, and increases insulin secretion.

Insulin treated group showed significant decrease in plasma glucose level and increased level of plasma insulin level when compared to untreated diabetic and L-Carnitine treated diabetic groups and this copes with (25). The decreased blood glucose level after insulin treatment was explained by increased glucose utilization in insulin sensitive peripheral tissues (26). Also insulin treatment has the ability to improve the glycemic control, insulin synthesis and secretion by pancreatic $\beta$-cells (27). As regard uterine contractility, there was poorer contractility in the diabetic samples whether arising spontaneously or induced by oxytocin. These results support (28) that demonstrated poor uterine contractility even in the presence of oxytocin and increased incidence of cesarean section in diabetic patients.

A previous study on myometrium from diabetic rats reported that oxytocin stimulation was similar to that in control rats (29), while McMurtie et al. (30) found maximal responses reduced. We found that diabetic uterus can respond to oxytocin but lower than the response of normal groups to oxytocin and this may be related to reduced $\mathrm{Ca}$ channel expression and intracellular calcium signals and a decrease in muscle mass (28).

Reduced uterine contractility in diabetes is multifactorial assuming involvement of oxidative stress, apoptosis, neuronal loss, and accumulation of glycated products (31). These disorders are probably due to the neuropathy, the damage of the pacemaker cells, and the myopathy caused by the hyperglycemia (32).

The reduced levels and ROS- induced $\mathrm{Ca}^{+2}$ desensitization in different smooth muscle organs
(33), obviously affected also uterus. There is a severe atrophy uterine sample as early as 15 days post DM by electron microscopic study that showed reduced myofibril number and destruction of smooth muscle cells in the diabetic myocardium compared to control (34)

L- Carnitine treated group showed an improvement in both spontaneous and oxytocin induced uterine contractility. Since, impaired uterine contractility in diabetes can be caused by several factors as oxidative stress, apoptosis, and neuropathy, L- Carnitine can improve uterine contractility by acting as antioxidant either by direct free radical scavenging, preventing free radical formation by inhibiting specific enzymes responsible for free radical production or by maintaining the integrity of electron transport chain of mitochondria in stress conditions

(35). Also L-Carnitine has anti-inflammatory (36), antiapoptotic and neuroprotective (37) effect which may have an important role in improvement in uterine contractility.

Also, insulin treated group showed significant improvement in both spontaneous and oxytocin induced uterine contractility as insulin has an important role in glucose homeostasis and improvement of the glycemic state in DM. DM is a chronic metabolic disease characterized by persistent hyperglycemia. Numerous studies have demonstrated that hyperglycemia can directly promote inflammatory response and oxidative stress (38).

It is possible that correction of hyperglycemia with insulin therapy can recover the activity of insulin signaling cascade and improve the muscle contractile function in DM (39). 
In line with uterine contractility changes, histological examination of uterine tissues from untreated diabetic group showed uterine endometrium with atrophied glands and inflammatory exudate in the supporting stroma also showed a marked reduction in the thickness of both endometrium and myometrium. These results cope with (40).

These changes may be due in part to the degeneration of the cells of endometrial columnar epithelium on one hand and that of the myocytes of the myometrium on the other (34). Also, these changes are attributed to hyperglycemia induced oxidative stress together with decline in protein synthesis and accelerated proteolysis in myofibrils which lead to inflammatory infiltration (41).

Treatment with L-Carnitine and insulin improved these structural changes, showing a greater improvement with combination treatment rather than individual one. The improvement with LCarnitine may be due to its effect on inhibition of protein degeneration, enhancement of protein synthesis, inhibition of inflammation and prevention of oxidative stress (42).

Insulin is an anabolic hormone which stimulate protein synthesis, also both mitochondrial and cytoplasmic protein synthesis were seen to be improved by insulin administration (43). Also, insulin exerts an anti-inflammatory response (39) which improves the inflammatory infiltrate.

\section{$\underline{\text { Refrences }}$}

1. Spiegl, G., Zupkó, I., Renáta Minorics, R.,Csik, G., Csonka, D., \& Falkay, G: Effects of experimentally induced diabetes Mellitus on pharmacologically and electrically Elicited myometrial contractility, Clinical and Experimental
Pharmacology and Physiology, 36, 884891, 2009.

2. Setji, T.L., Brown, A.J., \&Feinglos, M.N: Gestational diabetes mellitus.

Clin.Diabetes, 23, 17-24, 2005.

3. Evers, I.M., De Valk, H.., \&Visser, G.H: Risk of complications of pregnancy in women with type I diabetes: Nationwide prospective study in the Netherlands, B.M.J. (clinical research ed.), 328,915, 2004.

4. Dunne, F., Brydon, O., Smith, K.,\& Gee, H:Pregnancy in women with type 2 diabetes:12 years outcome data 1990 2002, Diabet. Med, 20,734-738, 2003.

5. Hedderson, M.M., Ferrara, A., \&Sacks, D.A: Gestational diabetes mellitus and lesser degree of pregnancy hyperglycemia: association with increased risk of spontaneous preterm birth, Obstet Gynecol, 102, 850-865, 2003.

6. Broderick, T.L., Quinney, H.A., \& Lopaschuk: Carnitine stimulation of glucose oxidation in the fatty acid perfused isolated working rat heart, GD.J Biol Chem, 267(6), 3758-63, 1992.

7. Nazari, Z., Nabiuni, M., Saeidi, M., \&Golalipour, M.J: Gestational diabetes leads to down-regulation of CDK4-pRBE2F1 pathway genes in pancreatic islets of rat offspring, Iran $J$ Basic Med Sci, 20(2),150-154, 2017.

8. Salama, R.H: Hypoglycemic effect of lipoic acid, carnitine and nigella sativa in diabetic rat model, Int $J$ Health (Qassim), 5(2):126-34, 2011. 
9. Unlüçerçi, Y., Bekpinar, S., Gürdöl, F., \&Seferoğlu, G.A: study on the relationship between homocysteine and diabetic nephropathy in rats, Pharmacol Res, 45(3), 249-52, 2002.

10. Klukovits, A., Gáspár, R., Sántha, P., Jancsó, G., \& Falkay, G: Functional and histochemical characterization of a uterine $\underline{\text { adrenergic denervation process in pregnant }}$ rats, Biol Reprod, 67(3), 1013-7, 2002.

11. De la Garza-Rodea, A.S, KnaänShanzer, S., Den Hartigh, J.D., Verhaegen, A.P, \&van Bekkum, D.W: Anomer-equilibrated streptozotocin solution for the induction of experimental diabetes in mice (Mus musculus), $J \mathrm{Am}$ Assoc Lab Anim Sci, 49(1), 40-4, 2010.

12. Saleem Mir, M., Maqbool Darzi, M., Khalil Baba, O., Khan,

H.M., Kamil, S.A., Sofi, A.H., \& $\underline{\text { Wani, }}$ S.A: Streptozotocin Induced Acute Clinical Effects in Rabbits (Oryctolagus cuniculus). Iran J Pathol, 10(3), 206-13, 2015.

13. Kim, H.J., Jung, B.H., Yoo, K.Y., Han, J.W., Um, H.S., Chang, B.S., \&Lee, J.K:

Determination of the critical diabetes duration in a streptozotocin-induced diabetic rat calvarial defect model for experimentation regarding bone regeneration. J Periodontal Implant Sci, 47(5), 339-350, 2017.

14. Waynforth, H.B., Flecknell, P.A: Experimental and surgical technique in the rat, Academic Press London 2nd ed, 66113, 1998.
15. Kelany, M.E., Alqahtani, S., Alkuriji, A., \&AI-Omar, S: Role of the antidiabetic drugs: Glibenclamide and metformin on the contractility of isolated rat uteri, Pak J Pharm Sci, 29(1),51-7, 2016.

16. Mostafa, A.F., Samir, S. M: What is the effect of ghrelin on rat uterine contractility in vitro?, J Basic Clin Physiol Pharmacol, 24(2):137-42, 2013.

17. Barham, D., Trinder, P: An improved colour reagent for the determination of blood glucose by the oxidase system, Analyst, 97(151),142-5, 1972.

18. Aughsteen, A.A., Khair, A.M., Suleiman, A.A: Quantitative morphometric study of the skeletal muscles of normal and streptozotocindiabetic rats, JOP, 7(4):382-9, 2006.

19. Uysal, N., Yalaz, G., Acikgoz, O., Gonenc, S., \&Kayatekin, B.M: Effect of L-carnitine on diabetogenic action of streptozotocin in rats, Neuro Endocrinol Lett, 26(4), 419-22, 2005.

20. Akbarzadeh, A., Norouzian, D., Mehrabi, M.R., Jamshidi, S.h., Farhangi, A., Verdi, A.A., Mofidian, S.M., \&Rad, B.L: Induction of diabetes by Streptozotocin in rats. Indian $J$ Clin Biochem, 22(2), 60-4, 2007.

21. Krishna, B., Rao, S., \&Satyana, M: Serum insulin levels and lipid profiles of streptozotocin induced diabetic wistar rats. J Indian Vet Assoc, 10, 22 - 6, 2012.

22. Bashi, A. Y. D., \& Al-Farha, M. A. A: Effect Of L-Carnitine On Certain Biochemical Parameters In Diabetic 
Patients. Tikrit Medical Journal, 16(1), 146-151, (2010).

23. Samir, S.M., Abbas, A.M., Safwat, S.M., \&Elserougy, H.G: Effect of L-carnitine on diabetes-induced changes of skeletal muscles in rats, $J$ Basic Clin Physiol Pharmacol, 29(1), 47-59, 2018.

24. Shahouzehi, B., Barkhordari, K., Aminizadeh, S., Masoumi-\&Ardakani, Y: Effect of L-carnitine administration on serum insulin and adiponectin levels, and AMPK, APPL1 and PPAR $\gamma$ gene expression in STZ-induced diabetic rat liver, Ukr.Biochem.J, 89(6), 48-55, 2017.

25. Abdel - Razek, a. d. h: Beneficial effect of L - carnitine on the neuromuscular performance in diabetic rats. $M M J, 23(2)$, 159 - 174, 2010.

26. Czech, M.P: $\quad$ New perspectives on the mechanism of insulin action, Recent Prog Horm Res, 40, 347-77, 1984.

27. Zhou, Y.S., Gao, Y., Guo, X.H., Li, B., Wang, S., \&Chi, J.M: Effects of timely insulin treatment on protection of beta cells in a rat model of type 2 diabetes mellitus. Chin Med J (Engl), 117(10), 1523-9, 2004.

28. Al-Qahtani, S., Heath, A., Quenby, S., Dawood, F., Floyd, R., Burdyga, T., \&Wray, S: Diabetes is associated with impairment of uterine contractility and high Caesarean section rate, Diabetologia, 55(2),489-98, 2012.

29. Jawerbaum, A., Catafau, J.R., Gonzalez, E.T., Novaro, V., Gómez, G., Gelpi, E., \& Gimeno,. MA: Eicosanoid production, metabolism and contractile activity in the isolated uterus from noninsulin-dependent diabetic rats during late pregnancy, Prostaglandins, 51(5), 30720, 1996.

30. McMurtrie, E.M., Ginsberg, G.G., Frederick, G.T., Kirkland, J.L., Stancel, G.M., \&Gardner, R.M: Effect of a diabetic state on myometrial ultrastructure and isolated uterine contractions in the rat, Proc Soc Exp Biol Med, 180(3), 497-5, 1985.

31. Chang, M.J., Xiao, J.H., Wang, Y., Yan, Y.L., Yang, J., \&Wang, J.L: 2, 3, 5, 4`Tetrahydroxystilbene-2-O-Beta-D-

Glucoside Improves Gastrointestinal Motility Disorders in STZ - Induced Diabetic Mice, PLoS One, 7(12), e50291, 2012.

32. Szarka, L.A., \& Camilleri, M: Stomach Dysfunction in Diabetes Mellitus: Emerging Technology and Pharmacology, J Diabetes Sci Technol, 4(1): 180-189, 2010.

33. Suzuki, H., Matsuzaki, J., \& Hibi, T: Ghrelin and Oxidative Stress in Gastrointestinal tract, $J$ Clin Biochem Nutr, 48(2), 122-125, 2011.

34. Tariq, S., Nurulain, S.M., Rashed, H., Lotfy, M., Emerald, S.B., Koturan, S., Tekes, K., \& Adeghate, E: Diabetesinduced changes in the morphology and nociceptinergic innervation of the rat uterus, J Mol Histol, 47(1), 21-33, 2016.

35. Surai, P.F: Silymarin as a Natural Antioxidant: An Overview of the Current Evidence and Perspectives, Antioxidants (Basel), 4(1), 204-47, 2015. 
36. Izgüt-Uysal, V.N., A ğaç, A., \&Derin, N: Effect of L-carnitine on carrageenaninduced inflammation in aged rats. Gerontology, 49(5), 287-92, 2003.

37. Dokmeci, D., Akpolat, M., Aydogdu, N., Uzal, C., Doganay, L., Turan, F. N:The protective effect of $\mathrm{L}$-carnitine on ionizing radiation- induced free oxgyn radical, $S$ cab J Lab Anim, 33, 75 83, 2006.

38. Hyun, E., Ramachandran, R., Hollenberg, M.D., \&Vergnolle, N: Mechanisms behind the anti-inflammatory actions of insulin, Crit Rev Immunol, 31(4),307-40, 2011.

39. Sun, Q., Li, J., \&Gao, F. New insights into insulin: The anti-inflammatory effect and its clinical relevance, World $J$ Diabetes, 5(2), 89-96, 2014.

40. Yildiz, M., \&Sandikci, M: Changes in the uterus and vagina of rats with experimentally induced diabetes and the effect of lycopene on the changes, Slov Vet Res, 53 (3), 151-60, 2016.
41. Shi, J.Z., Zhang, S.S., Zhang, Z., Liang, Q., Shi, Y., Hua, J.L., \&Sun, T: Expressions of sperm-specific genes in carnitine-cultured testis sperm of obstructive azoospermia patients. Zhonghua Nan Ke Xue, 16,504509, 2010.

42. Ringseis, R., Keller, J., \&Eder, K: Mechanisms underlying the anti-wasting effect of L-carnitine supplementation under pathologic conditions: evidence from experimental and clinical studies, Eur J Nutr, 52(5), 1421-42, 2013.

43. Biolo, G., Declan Fleming, R.Y., \&Wolfe, R. R: $\underline{\text { Physiologic }}$ hyperinsulinemia stimulates protein synthesis and enhances transport of selected amino acids in human skeletal muscle. J Clin Invest, 95(2), 811- 9, 1995. 